\title{
Multifocal Fixed Drug Eruption Induced by Mefenamic Acid
}

\section{Mohamed M1*, Nabli N1, Njim L ${ }^{2}$, Soua $\mathrm{Y}^{1}$, Fredj NB ${ }^{3}$, Aouem $\mathrm{K}^{3}$ and Zili J ${ }^{1}$}

${ }^{1}$ Department of Dermatology, Monastir University Hospital, Tunisia

${ }^{2}$ Department of Pathology, Monastir University Hospital, Tunisia

${ }^{3}$ Department of Parmacology, Monastir, Tunisia

\section{Case Report \\ Volume 1 Issue 1}

Received Date: November 09, 2016

Published Date: November 28, 2016

DOI: $10.23880 /$ cdoaj16000103

*Corresponding author: Mariem Mohamed, Department of Dermatology, Monastir University Hospital, Faculty of Medicine of Monastir, Monastir, Tunisia, E-mail: mariemmohamed79@yahoo.fr

\section{Abstract}

Mefenamic acid is a nonsteroidal anti-inflammatory inhibitor of cyclooxygenase 1 and 2. It is rarely reported to induce fixed drug eruption (FDE). We report on a new case of a multifocal fixed drug eruption caused by mefenamic acid and confirmed by patch test.

Keywords: Mefenamic acid; Fixed drug eruption; Pruritus; Hyperpigmentation; Erythematous

\section{Case Report}

A 47-year-old woman with a 2-year history of renal failure were presented at our department for pruritic, erythematous and hyperpigmented patches, $1-3 \mathrm{~cm}$ in diameter, on the face, trunk and extremities. Some lesions were covered with blisters and erosions (Figure 1). The patient reported that the eruption began 1 year earlier. In this year, it occurred many times and resolved spontaneously after few weeks with residual hyperpigmentation. It became more spread and more worsen from time to time. The patient noticed also that the lesions became inflamed within a few hours of taking mefenamic acid for dysmenorrhoea.

Routine laboratory tests revealed elevated parameters of inflammation (CRP, ESR, leukocytosis), elevated creatinine rate and anemia related to his renal failure. Skin biopsy of erythematous lesion showed vacuolar interface dermatitis with necrotic keratinocytes and a predominantly lymphohistiocytic inflammatory infiltrate with neutrophils and eosinophils (Figure 2).

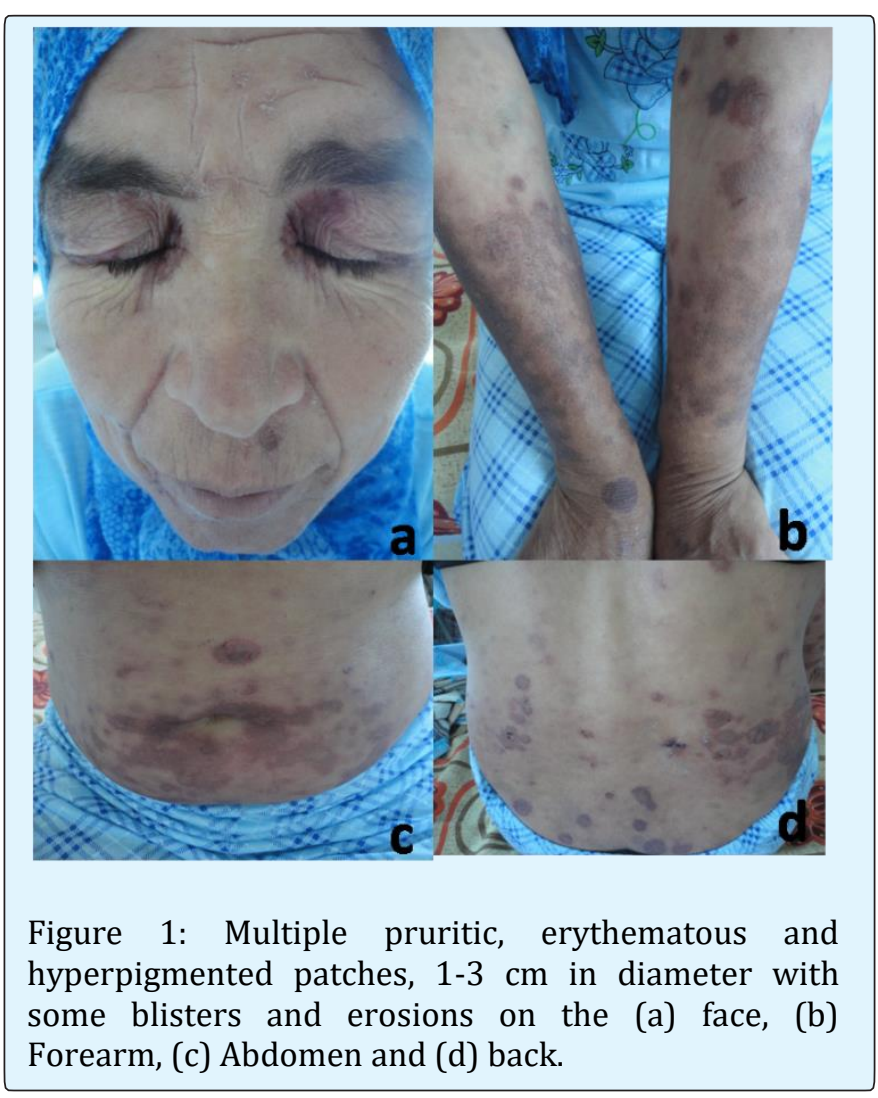




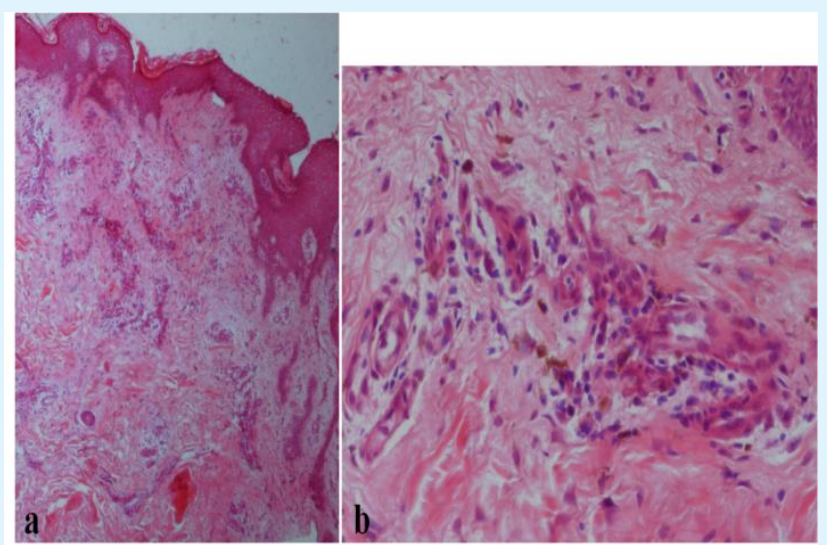

Figure 2: Vacuolar interface dermatitis with necrotic keratinocytes and a predominantly lymphohistiocytic inflammatory infiltrate with neutrophils and eosinophils; (a) H and E X 40 and (b) Hand E X 200.

Based on the clinical and histopathologic findings, a diagnosis of multifocal FDE due to mefenamic acid was made. Patch tests performed with Mefaminic Acid 30\% in petrolatum applied directly to healthy and lesional skin were positive (Figure 3). The patient was advised to stop taking mefenamic acid and since that, there have been no further episodes of inflammation after a mean follow-up of 1 year.

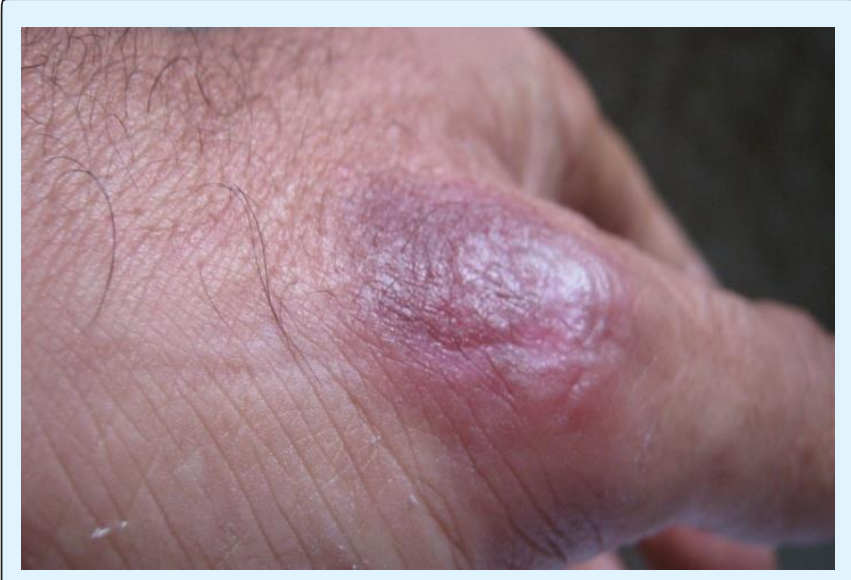

Figure 3: Positive reaction of patch test performed with Mefaminic acid $30 \%$ in petrolatum.

\section{Discussion}

Fixed drug eruption was first described by Bourns [1] in 1889. It is defined by the appearance of lesions at always the identical location after repeated exposure to the responsible drug [2]. It represents a IVc type druginduced reaction of the skin and mucous membranes [3].
Fixed drug eruption can affect any age group from childhood to older age, but most commonly individuals aged 20-40 years [4]. Association with HLA-B22 has been reported [5]. Cutaneous and mucous membrane lesions appear minutes to hours after administration of the sensitizing medication [6]. They are observed most frequently after oral administration than intravenous, intramuscular administration or topical application [4]. Occurrence after sexual contact with a partner who had taken the eliciting drug has been reported [7]. Clinically, FDE is characterized by the sudden appearance of one or several round, sharply defined erythematous maculae on the skin or mucous membranes after drug administration. The lesions have a size of several millimeters up to $10 \mathrm{~cm}$. they can rapidly progress to edematous plaques and can occasionally vesiculate or blister. On the mucous membranes, erosions are often seen. Sites of predilection are the palms and soles, the medial aspects of the limbs, abdomen, but also lips, tongue, oral mucosa and in men the glans penis.

The lesions are often asymptomatic, but burning and pruritus at the involved sites are reported $[6,8]$.

Rarely, systemic signs and symptoms such as malaise, anorexia, fever, diarrhea, nausea and abdominal complaints occur.

A wide range of drugs can trigger FDE, but the most common ones are antibiotics (particularly cotrimoxazole), anticonvulsants, and analgesics.

The most common offending agents include antimicrobials mainly co-trimoxazole, nonsteroidal antiinflammatory drugs, and antiepileptics [4].

Mefenamic acid, an anthranilic acid derivative, is a nonsteroidal anti-inflammatory anti-rheumatic drug. It has analgesic, antiphlogistic and antipyretic effects via inhibition of prostaglandin synthesis. It is used to treat acute and chronic pain such as in rheumatic diseases, primary dysmenorrhea, after trauma and surgery as well as muscular and spinal pain.

Mefenamic acid is frequently taken without any medical advice. The association of the drug with a possible FDE may be difficult because the use of mefenamic acid is occasional and usually forgotten by the patients. Only few cases of PFE induced by mefaminic acid have been reported [9-12]. In the diagnostic work-up of fixed drug eruption, provocation tests represent the gold standard [4]. Patch testing with the presumed drug will give positive results mainly when it is applied to the 


\section{Clinical Dermatology Open Access Journal}

affected skin. In our case, patch tests with Mefaminic Acid $30 \%$ in petrolatum applied to lesional skin were positive.

\section{References}

1. Bourns DCG (1889) Unusual effects of antipyrine. $\mathrm{Br}$ Med J 2: 218-220.

2. Brocq L (1984) Eruption érythémato- pigmentée fixe due a l'antipyrine. Ann Dermatol Vénéréol 5: 308313.

3. Posadas SJ, Pichler WJ (2007) Delayed drug hypersensitivity reactions - new concepts. Clin Exp Allergy 37(7): 989-999

4. Mahboob A, Haroon TS (1998) Drugs causing fixed eruptions: a study of 450 cases. Int Dermatol 37(11): 833-838.

5. Pellicano R, Ciavarella G, Lomuto M, Di Giorgio G (1994) Genetic susceptibility to fixed drug eruption: evidence for a link with HLA-B22. J Am Acad Dermatol 30(1): 52-54.

6. Ozkaya E (2008) Fixed drug eruption: state of the art. J Dtsch Dermatol Ges 6(3): 181-188.
7. Gruber F, Stasi c A, Lenkovi c M, Brajac I (1997) Postcoital fixed drug eruption in a man sensitive to trimethoprim-sulphamethoxazole. Clin Exp Dermatol 22(3): 144-145.

8. Bilgili SG, Calka O, Karadag AS, Akdeniz N, Kosem M (2012) Nonsteroidal anti-inflammatory drugsinduced generalized fixed drug eruption: two cases. Hum Exp Toxicol 31(2): 197-200.

9. Long CC, Finlay AY, Marks R (1992) Fixed drug eruption to mefenamic acid: a report of three cases. Br J Dermatol 126(4): 409-411.

10. Watson A, Watt G (1986) Fixed drug eruption to mefenamic acid. Australas J Dermatol 27(1): 6-7.

11. Muto M, Nichimura M, Kimura H (1988) Fixed drug eruption due to mefenamic. Acta Dermatol-Kyoto 83: 193-195.

12. A Handisurya, Moritz KB, Riedl E, Reinisch C, Stingl G, et al. (2011) Fixed drug eruption caused by mefenamic acid: a case series and diagnostic algorithms. JDDG 9(5): 374-378. 